\title{
The MYST histone acetyltransferases are essential for gametophyte development in Arabidopsis
}

\author{
David Latrasse, Moussa Benhamed, Yves Henry, Séverine Domenichini, \\ Wanhui Kim, Dao-Xiu Zhou and Marianne Delarue*
}

Address: Institut de Biotechnologie des Plantes, CNRS UMR8618, Université Paris-sud XI, 91405 Orsay, France

Email: David Latrasse - david.latrasse@u-psud.fr; Moussa Benhamed - moussa.benhamed@u-psud.fr; Yves Henry - yves.henry@u-psud.fr; Séverine Domenichini - severine.domenichini@u-psud.fr; Wanhui Kim - wanhui.kim@u-psud.fr; Dao-Xiu Zhou - dao-xiu.zhou@u-psud.fr; Marianne Delarue* - marianne.delarue@u-psud.fr

* Corresponding author

Published: 28 November 2008

BMC Plant Biology 2008, 8:121

doi: $|0.1| 86 /|47|-2229-8-12 \mid$

Received: 7 July 2008

Accepted: 28 November 2008

This article is available from: http://www.biomedcentral.com/I47|-2229/8/I2I

(c) 2008 Latrasse et al; licensee BioMed Central Ltd.

This is an Open Access article distributed under the terms of the Creative Commons Attribution License (http://creativecommons.org/licenses/by/2.0), which permits unrestricted use, distribution, and reproduction in any medium, provided the original work is properly cited.

\begin{abstract}
Background: Histone acetyltransferases (HATs) play critical roles in the regulation of chromatin structure and gene expression. Arabidopsis genome contains 12 HAT genes, but the biological functions of many of them are still unknown. In this work, we studied the evolutionary relationship and cellular functions of the two Arabidopsis HAT genes homologous to the MYST family members.
\end{abstract}

Results: An extensive phylogenetic analysis of 105 MYST proteins revealed that they can be divided into 5 classes, each of which contains a specific combination of protein modules. The two Arabidopsis MYST proteins, HAMI and HAM2, belong to a "green clade", clearly separated from other families of HATs. Using a reverse genetic approach, we show that HAMI and HAM2 are a functionally redundant pair of genes, as single Arabidopsis ham I and ham 2 mutants displayed a wildtype phenotype, while no double mutant seedling could be recovered. Genetic analysis and cytological study revealed that ham I ham 2 double mutation induced severe defects in the formation of male and female gametophyte, resulting in an arrest of mitotic cell cycle at early stages of gametogenesis. RT-PCR experiments and the analysis of transgenic plants expressing the GUS reporter gene under the HAMI or the HAM2 promoter showed that both genes displayed an overlapping expression pattern, mainly in growing organs such as shoots and flower buds.

Conclusion: The work presented here reveals novel properties for MYST HATs in Arabidopsis. In addition to providing an evolutionary relationship of this large protein family, we show the evidence of a link between MYST and gamete formation as previously suggested in mammalian cells. A possible function of the Arabidopsis MYST protein-mediated histone acetylation during cell division is suggested. 


\section{Background}

Eukaryotic genomic DNA is packaged around octamers of histones to form the basic structural units of chromatin, the nucleosomes. Chromatin is the functional template for a variety of key biological processes, such as DNA replication, repair of DNA damage, recombination, and transcription.

Covalent modifications of the amino-terminal tails of the core histones affect nucleosome positioning and compaction, and therefore play pivotal roles in chromatin remodelling and in gene regulation. Histone modifications include acetylation, methylation, phosphorylation, ubiquitination, sumoylation and poly-ADP-ribosylation $[1,2]$. Among these modifications, acetylation of histones appears as a key switch for inter-conversion between permissive and repressive states of chromatin domains and as in other eukaryotes, histone acetylation and deacetylation play important roles in the regulation of plant gene expression. In general, hyperacetylation of histones relaxes chromatin structure and is associated with transcriptional activation, whereas hypoacetylation of histones induces chromatin compaction and gene repression, although a more sophisticated and nuanced chromatin language is likely to yield dynamic functional outcomes [3]. Acetylation of histones provides also an epigenetic marker for gene expression because it blocks association of heterochromatin-stabilising complexes [4].

The homeostatic balance of nucleosomal histone acetylation is maintained by antagonistic action of histone acetyltransferases (HAT) and histone deacetylases (HDAC), which are the best-characterized enzymes among histone modifier factors. In Arabidopsis, the HAT group contains 12 members divided into four classes based on sequence homology and mode of action: GNAT (Gcn5-related N-acetyltransferase), p300/CBP, TAF 250 and MYST (MOZ, YbF2, Sas2, Tip60-like) families [5,6].

Numerous reports have linked specific histone acetyltransferases to transcriptional regulation in Arabidopsis. For instance, we and other have shown that GCN5, plays a role in the regulation of numerous processes, including cold tolerance, floral development, embryonic cell-fate patterning, and light responsiveness [7-11]. HAF2, one of the two TAF 250 homologs in Arabidopsis is necessary for upregulating the transcription of light-induced genes $[10,12]$. HAC1, HAC5 and HAC12 of the CBP family have been shown to be involved in regulating flowering time [13]. Functions for other predicted Arabidopsis HATs have not yet been determined.

In mammals, the MYST family is the largest and most divergent. It has been intensely studied because of its broad conservation and biological significance. Experi- ments performed in the last few years show that MYST family proteins are involved in a wide range of cell function ranging from transcription activation and silencing, apoptosis, cell cycle progression, DNA replication or DNA repair with often a link to pathological disorder such as cancer (reviewed by [14-16]). For instance, Histone acetyltransferase bound to ORC (Hbol) has been shown to interact both with ORC7 and with MCM2, essential proteins of the pre-replication complex (Pre-RC) $[17,18]$ and to positively regulate pre-RC assembly and initiation of DNA-replication [19-21]. Another mammalian MYST protein, HIV tat-interacting protein 60 (Tip60), seems to be a functional homologue of the yeast protein Esa1 [22], which is the only essential HAT for yeast viability, playing a role in cell cycle progression [23]. It appears that this function has been conserved during evolution and several recent results provide evidence that Tip60 is a key protein in regulating cell cycle progression in higher organisms. Likewise, a broad range of functions has been ascribed to Tip60 as its involvement in DNA repair or regulation of apoptosis (reviewed by [15]). MORF (monocytic leukaemia zinc finger protein-related factor) may be involved in early mammalian gametogenesis [24], whereas the mouse orthologue, Querkopf, has been implicated in neural development and maintenance of neural stem cells [25]. At last, it has been recently shown, that Mof (Males absent on the first) is essential for progression of embryonic development in mice $[26,27]$.

Two MYST family members (HAM1 and HAM2) are present in the $A$. thaliana genome [6]. They were demonstrated to possess an in vitro HAT activity specific for lysine 5 of histone H4 (H4K5) [28]. However, the relevance of such observations to the biological roles of HAM1 and HAM2 has not been addressed.

Here, we report on the phylogenetic analysis of MYST family, which appears clearly separate from other families of HAT. By analyzing loss-of-function lines in Arabidopsis, we show that the two members of this family are functionally redundant, and provide evidence that they are required post-meiotically for important cellular process during the formation of both the male and female gametes.

\section{Results \\ Phylogenetic analysis of MYST proteins}

Initially, members of the MYST group were classified as putative acetyltransferases based on a region in the MYST domain that is homologous to the canonical acetyl-CoA binding domain (motif A) found in GNAT superfamily acetyltransferases [29]. The Arabidopsis genome encodes two closely related MYST family proteins HAM1 and HAM2 (87.9\% identity, $92.5 \%$ similarity in amino-acid sequences), also known as respectively HAG4 and HAG5 
[6]. Wolfe data http://wolfe.gen.tcd.ie/ postulated that HAM1 (At5g64610) and HAM2 (At5g09740) resulted from a duplication event, the $\alpha$ event according to [30], produced by a polyploidization in the Brassicaceae ancestor. The Arabidopsis thaliana HAM1 and HAM2 genes show a Ks value of 0.84 . In their measure of divergence between duplicated genes, De Bodt et al. (2005) [31] conclude that the most recent polyploidization event corresponds to a modal Ks value between 0,7 and 0,9. This reinforce the previous observation that the HAM1 and HAM2 genes from Arabidopsis belong to duplicated segments produced by the most recent polyploidization event in the Brassicaceae ancestor.

In order to identify the closest sequences to HAM1 and HAM2, a phylogenetic analysis of the MYST proteins was performed by an extensive search in available databases. Amino acid alignements of the MYST domain were used as the basis for classifying MYST proteins. Fig. 1A shows an unrooted phylogenetic tree illustrating the relationship between 105 MYST proteins (listed in Additional file 1) selected on a total of 130 .

The MYST family is divided into five unrelated classes, i.e. not related by significant bootstrap values. The class I comprises proteins from the green lineage including the Arabidopsis HAM1 and HAM2 sequences, two clades of sequences from Mammals, Teleostei, Insects and Cnidarian, and clades of sequences from Alveolata, Fungi, Nematods and Plathelminthes. The class II (bootstrap 79\%) groups sequences of Fungi plus one sequence of insect. Classes III and IV (bootstrap 98\% and 93\%) are exclusively composed of sequences from Fungi. The class $\mathrm{V}$ (bootstrap 96\%) enclosed sequences from Teleostei, Archausauria, Mammals and Insects. Three sequences (from Human, Insect and Ascidiaceae) form a small additionnal group (bootstrap 84\%).

We also noticed that the MYST proteins from the green lineage (Eudicots and Monocots Angiosperms, Gymnosperms, Bryophytes, Chlorophyceae and Prasinophyceae) lie within a cluster supported by a significant bootstrap value $(86 \%)$. This cluster is associated both with two sequences of Alveolata and 2 sequences of Dictyostelium discoideum, as is frequently observed for sequences from plants. A second cluster of MYST sequence from Prasinophyceae (Ostreococus) is observed. The green lineage phylogenetic tree appears robust with highly significant bootstrap values (Additional file 2). Members of the MYST family of acetyltransferases possess several protein domains. Structural analysis by using Pfam and SMART tools revealed that within each previously defined group, domain organizations of the MYST proteins are highly similar (Fig. 1B). Class I members possess a chromodomain (PF 00385) in the amino-terminus and a zinc finger
(C2H2 type) contiguous to a MOZ-SAS acetyltransferase domain (PF 01853). The structure is reduced to the zinc finger and MOZ-SAS domains in classes II and III. Class IV possesses a PHD finger (plant homeodomain zinc finger, PF 00628) in the amino-terminus and a central MOZ-SAS domain. Finally, sequences from class $\mathrm{V}$ were much longer, with a linker histone $\mathrm{H} 1$ and $\mathrm{H} 5$ family domain (PF 00538), one or two PHD finger domain, both at the amino terminus, a $\mathrm{C} 2 \mathrm{H} 2$ type zinc finger, contiguous to the MOZ-SAS domain and an extensin-like region (PF04554) at the carboxy terminus. The observed domain organization and protein sizes reinforced the idea of existence of several distinct MYST subfamilies.

\section{Loss-of-Function mutations at the HAMI and HAM2 loci} In order to study the developmental function of plant MYST genes, a search in Arabidopsis T-DNA insertion mutant collections was performed. Three insertion lines in HAM1 gene were identified. HAM1 mutants, ham1-1, ham1-2 and ham1-3, disrupt the predicted coding region at 155, 1973 and $1959 \mathrm{bp}$ in the genomic DNA and downstream of the initiation codon, respectively (Fig. 2A). A single insertion line, ham2, was identified in HAM2 gene. The T-DNA insert is located 809 bp downstream of the ATG (Fig. 2A). All these mutants are in Columbia-0 (Col0) background, except for ham1-3 in the Wassilewskija (Ws) background.

Homozygous insertion plants were identified by PCR. RTPCR experiments, with primers that span the insertion sites, were neither able to detect any HAM1 mRNA in the ham 1 mutants nor HAM2 mRNA in ham 2 mutant (Fig. $2 \mathrm{~B})$. There were no changes in the level of HAM2 mRNA in ham 1 mutants lines compared with control. Similarly, HAM1 mRNA was unchanged in ham 2 homozygous plants (Additional file 3). This indicates that the absence of one HAM transcript does not affect expression of the other.

We did not observed any abnormal phenotype in plants homozygous for either ham 1 or ham 2 mutations when grown under standard conditions. In addition, each of the mutant alleles displayed a normal Mendelian segregation ratio (data not shown). As HAM1 and HAM2 are closely related genes, functional redundancy might exist to prevent the appearance of a mutant phenotype in the homozygous mutant lines. Therefore, ham 1-1, ham1-2 and ham 1-3 homozygous plants were respectively crossed with ham 2 homozygous plants to create double mutants. The resulting double-heterozygous $\mathrm{F} 1$ were allowed to be self-fertilized and individuals from the resulting progeny were genotyped using PCR. For each crosses, from more than $120 \mathrm{~F} 2$ individuals, no homozygous double mutants were detected. However, plants homozygous for insertion at one locus and heterozygous at the other were found. 
A
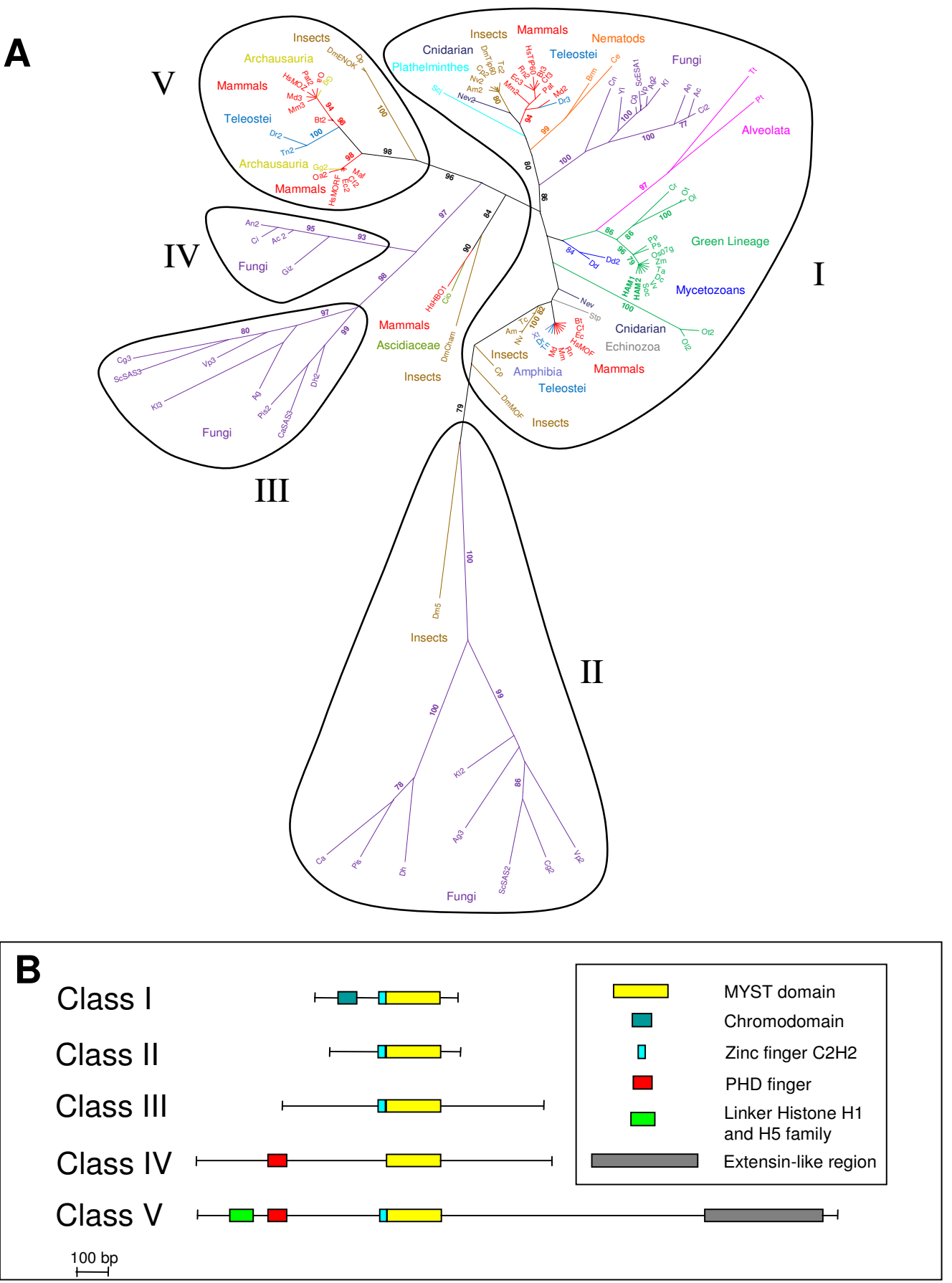

Figure 1

\section{Figure I}

Phylogenetic tree and domain organization of the MYST family of HAT. (A) Numbers refer to the bootstrap values. The figure shows an unrooted phylogenetic tree based on an extensive search in available databases. The tree contains 105 sequences selected on a total of I 30 obtaining by an extensive BLAST search. The plant lineage is shown in green, mammals are in red and fungi in purple. The MYST family is divided into five unrelated classes displaying similar domains organization. (B) Domain organization of the MYST proteins in the five classes previously defined in (A). 
A
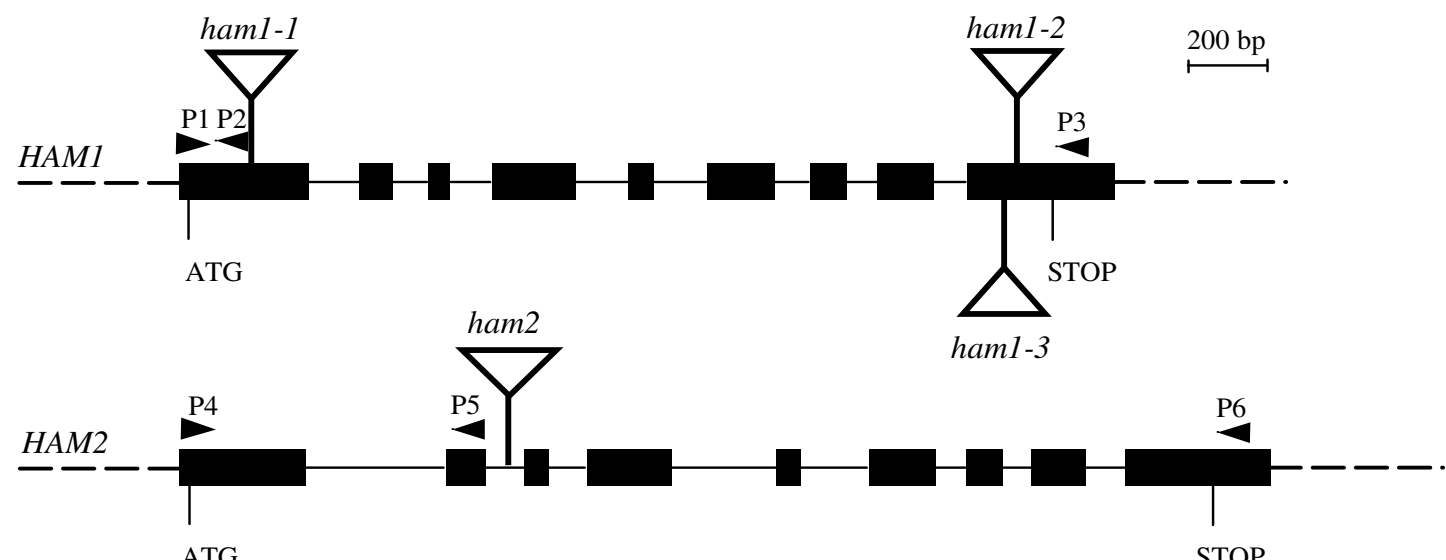

B

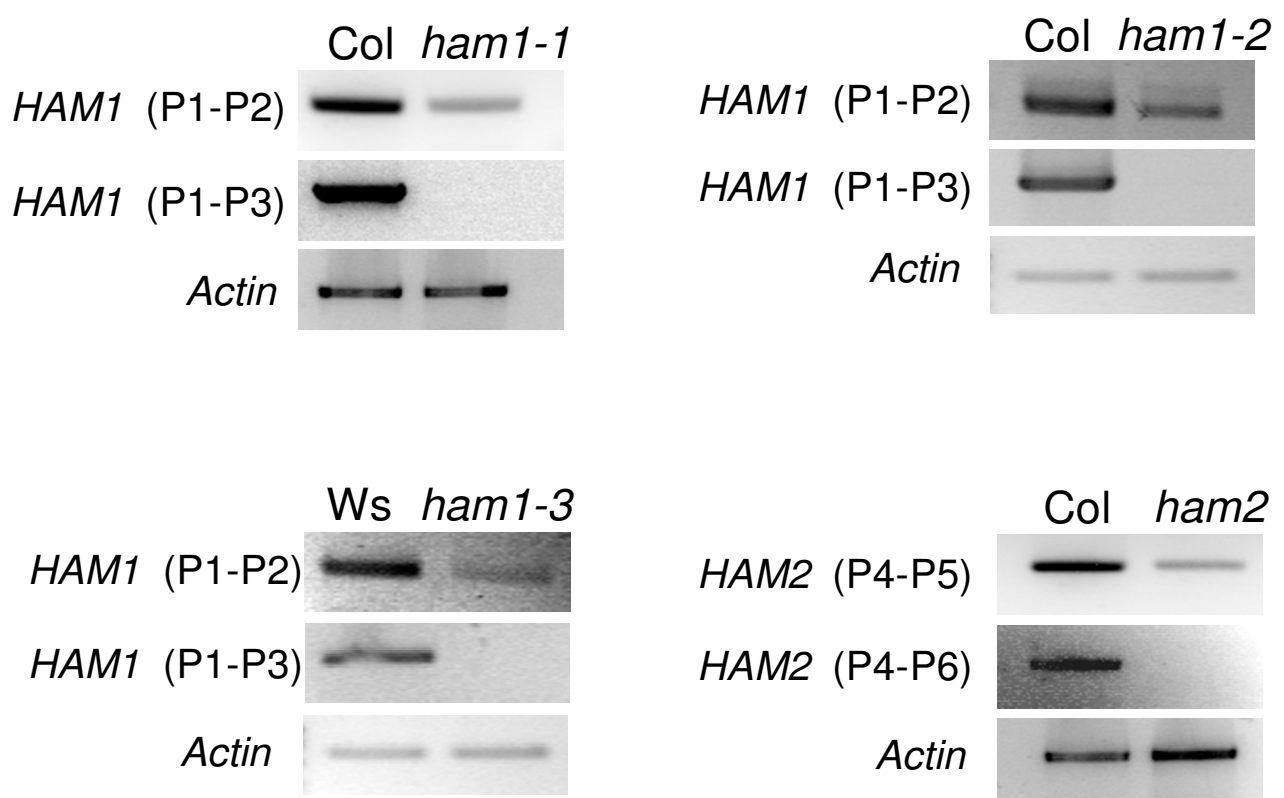

Figure 2

Characterization of T-DNA insertion mutations within HAMI and HAM2. (A) Schematic representation of the TDNA insertions in the HAMI and HAM2 genes. Black boxes and solid lines denote exons and introns, respectively. The filled triangles represent the six PCR primers used in RT-PCR (see "Methods"). (B) RT-PCR analysis of HAM genes expression in homozygous insertion mutants and wild-type seedlings with primer pairs PI-P2, PI-P3, P4-P5 and P4-P6 as indicated in (A). 
Such plants with either the genotype HAM1/ham1; ham2/ ham2 or ham1/ham1; HAM2/ham2 were allowed to selfpollinate. For this F3 population, the expected frequency of ham 1 ham 2 plants is $25 \%$. From 166 seedlings from a HAM1/ham1-1; ham2/ham2 parent, no ham1-1ham2 plants were found (Additional file 4, line1). From 162 seedlings from a ham1-1/ham1-1; HAM2/ham2 parent, no ham1-1 ham 2 plants were found (Additional file 4, line 2). These data strongly indicate that ham1ham 2 double mutant plants are not viable. Because F2 and F3 seeds appeared to be $100 \%$ viable, without seedling lethality after germination (data not shown), the loss of a double mutant plant must have occurred early during seed development or before fertilization and suggested that HAM1 and HAM2 have a redundant but important function for Arabidopsis embryo development and/or male/female gametophyte formation.

\section{ham I ham 2 double mutant is affected in gametogenesis}

If only the ham1ham 2 developing seeds were not viable, then the progeny of self-fertilize ham1/ham1; HAM2/ham2 and HAM1/ham1; ham2/ham2 plants allowed to self-fertilize would segregate $2 / 1$ for heterozygous and homozygous wild type at the heterozygous locus of the parent. However, the observation was that the percentage of heterozygous seedlings was much less than $67 \%$, with only $32.5 \%$ heterozygous at the HAM 1 locus and $18.5 \%$ heterozygous at the HAM2 locus (Additional file 4, lines 1 and 2). This deviation from a standard inheritance pattern implies death of more than just the double null developing seed.

To confirm this hypothesis, the fertility of ham1/ham1; HAM2/ham 2 and HAM1/ham1; ham2/ham2 mutants was determined after self-fertilization and compared to the wild-type. For different genotypes, the length of the siliques was reduced (Fig. 3A). For example, in the case of the HAM1/ham1-1; ham2/ham2 sesquimutant, the length of the siliques was $1.02 \pm 0.10 \mathrm{~cm}$ compared to $1.44 \pm$ $0.15 \mathrm{~cm}$ for the wild-type $(\mathrm{n}=40)$. The number of seeds per silique was significantly reduced compared to wildtype siblings and was greater than the $25 \%$ loss expected by loss of the double mutant (Table 1 ). In addition, dissected siliques illustrated that unfertilized ovules were presents (Fig. 3B). This suggests that the loss of inheritance of the mutant allele occurred early, as a result of female gametophyte death.

To distinguish between arrested in embryo development and abnormalities in gametophytes, reciprocal crosses were performed to analyse inheritance via gametophytes. The null alleles, were successfully inherited from male gamete for both loci, although at a rate reduced from the expected 50\% frequency (Additional file 4 , lines 3 to 6 ). When pollen grains of the HAM1/ham1-1; ham2/ham 2 or ham1-1/ham1-1; HAM2/ham2 mutants were used to pollinate the stigma of the wild-type female parent, the number of seeds was not significantly different from those observed in the wild-type (Table 1; lines 12 and 14). The frequency of inheritance of the ham allele from the male was $15.5 \%$ for ham 1 and $9 \%$ for ham 2 (Additional file 4, lines 4 and 6 ).

When HAM1/ham1-1; ham2/ham2 or ham1-1/ham1-1; HAM2/ham 2 mutants were used as female parent, cleared siliques from these crosses showed that female gametophyte development was arrested in approximately one half of the ovules (Table 1; lines 13 and 15). This finding suggests that aborted ovules may correspond to a female gamete ham1ham2. Genotyping of the progenies confirmed that the inheritance of the ham alleles from the female was null for ham1 and ham2 (Additional file 4; lines 3 and 5).

To track the expression stage of the ham 1 ham 2 mutations, we therefore examined the viability of pollens of the mutants. Pollens collected from wild-type and mutants bearing one copy of either HAM1 or HAM2 were stained with Alexander solution, which stained mature viable pollen grains as purple and dead or dying ones as dark green. The majority of examined pollens from wild-type were viable (Fig. 3C and 3E) with very few dead ones. In anthers of ham1-1/ham1-1; HAM2/ham2 mutants, however, only approximately $60 \%$ of pollens grains showed a staining pattern similar to that of the wild-type, the remaining were stained as dark green $(n=1400$; Fig. 3D and $3 \mathrm{~F}$ ). These data are consistant with the reduce transmission of ham 2 allele describe previously (Additional file 4). Morphologically, the dead pollens were misshapen and smaller (Fig. 3H), which could easily be distinguished from wild-type pollens (Fig. 3G).

We further analyzed male gametophyte development in the double mutant by fluorescence and microscopy. The pollen grain is the male gametophyte in Angiosperms. During microsporogenesis, meiosis of the microspore mother cell produces a tetrad of microspores. After release from the tetrad, during microgametogenesis, each microspore goes through an asymmetric cell division, pollen mitosis I (PMI), to produce a bicellular pollen grain containing a generative cell and a much larger vegetative cell. Only the smaller generative cell undergoes a second round of cell division, pollen mitosis II, to produce two sperm cells $[32,33]$. Pollen grains collected from open flowers of both wild-type and mutants bearing one copy of either HAM1 or HAM2, were examined by staining with DNA-specific dye 4',6-diamidino-2-phenylindole (DAPI). When wild-type flowers were open, pollen grains were already mature, and they had two brightly stained sperm nuclei and a faintly stained vegetative nucleus (Fig. 4C). In 
Table I: Genetic analysis and transmission of ham I and ham2 mutations

\begin{tabular}{|c|c|c|c|c|c|c|}
\hline & $\begin{array}{l}\text { Genotype of the } \\
\text { parents } \\
\text { Female } \times \text { Male }\end{array}$ & $\begin{array}{l}\text { Total numbers of } \\
\text { developing seeds }\end{array}$ & $\begin{array}{l}\text { Total numbers of } \\
\text { unfertilized ovules }\end{array}$ & $\mathbf{N}$ & $\begin{array}{l}\text { Percentages of } \\
\text { unfertilized ovules }\end{array}$ & $P$-value a \\
\hline I & $\begin{array}{l}\text { HAMI/HAMI;HAM2/HAM2 } \\
\text { selfed }\end{array}$ & 280 & 11 & 291 & 3.8 & 0 \\
\hline 2 & $\begin{array}{l}\text { HAMI/HAMI;ham2/ham2 } \\
\text { selfed }\end{array}$ & 294 & 10 & 304 & 3.3 & 0 \\
\hline 3 & $\begin{array}{l}\text { ham I-I/ham I-I;HAM2I } \\
\text { HAM2 selfed }\end{array}$ & 318 & 7 & 325 & 2.2 & 0 \\
\hline 4 & $\begin{array}{l}\text { ham I-I/ham I-I;HAM2I } \\
\text { ham2 selfed }\end{array}$ & 139 & 141 & 280 & 50.4 & 0.905 \\
\hline 5 & $\begin{array}{l}\text { HAMI/ham I-I;ham2/ham2 } \\
\text { selfed }\end{array}$ & 161 & 157 & 318 & 49.4 & 0.822 \\
\hline 6 & $\begin{array}{l}\text { ham I-2/ham I-2;HAM2I } \\
\text { HAM2 selfed }\end{array}$ & 362 & 12 & 374 & 3.2 & 0 \\
\hline 7 & $\begin{array}{l}\text { ham 1-2/ham I-2; HAM2/ } \\
\text { ham2 selfed }\end{array}$ & 163 & 157 & 320 & 49.1 & 0.737 \\
\hline 8 & $\begin{array}{l}\text { HAM I/ham I-2;ham2/ham2 } \\
\text { selfed }\end{array}$ & 196 & 201 & 397 & 50.6 & 0.801 \\
\hline 9 & $\begin{array}{l}\text { ham 1-3/ham I-3; HAM2/ } \\
\text { HAM2 selfed }\end{array}$ & 302 & 12 & 314 & 3.8 & 0 \\
\hline 10 & $\begin{array}{l}\text { ham I-3/ham I-3;HAM2I } \\
\text { ham2 selfed }\end{array}$ & 229 & 235 & 464 & 50.6 & 0.781 \\
\hline II & $\begin{array}{l}\text { HAM I/ham I-3;ham2/ham2 } \\
\text { selfed }\end{array}$ & 112 & 115 & 227 & 50.7 & 0.841 \\
\hline 12 & $\begin{array}{l}\text { WT } \times \text { ham I-I//ham I- } \\
\text { I;HAM2/ham2 }\end{array}$ & 125 & 4 & 129 & 3.1 & 0 \\
\hline 13 & $\begin{array}{l}\text { ham I-I/HAMI;ham2/ham2 } \\
\times \text { WT }\end{array}$ & 62 & 59 & 121 & 48.8 & 0.785 \\
\hline 14 & $\begin{array}{l}\text { WT } \times \text { ham I-I/HAM I; ham2/ } \\
\text { ham2 }\end{array}$ & 74 & 2 & 76 & 1.3 & 0 \\
\hline 15 & $\begin{array}{l}\text { ham I-I/ham I-I;HAM2I } \\
\text { ham2 × WT }\end{array}$ & 52 & 55 & 107 & 51.4 & 0.771 \\
\hline
\end{tabular}

Between 10 and 15 siliques from the main inflorescence stem of 5 -week-old plants were manually dissected and scored for aborted ovules.

a Two-tailed P-values represent the fit of the data to an expected segregation of $1: I$ wild type: aborted.

single mutant plants, microsporogenesis proceeds normally (Additional file 5). By contrast, a part of pollens derived from HAM1/ham1-1; ham2/ham2 and ham1-1/ ham1-1; HAM2/ham2 sesquimutant flowers displayed one large DNA mass $(\sim 36 \%, \mathrm{n}=280$; Fig. $4 \mathrm{E}$ and $4 \mathrm{~F})$. These observations suggest that the degeneration of ham 1 ham 2 double mutant pollens occurred mainly at the uninucleated stage before the first pollen mitosis (PM I).

On the female side, during megagametogenesis, meiosis of the megaspore mother cell gives rise to four megaspores, but three degenerates and one survives. This cell undergoes three round of mitosis to form a seven- 

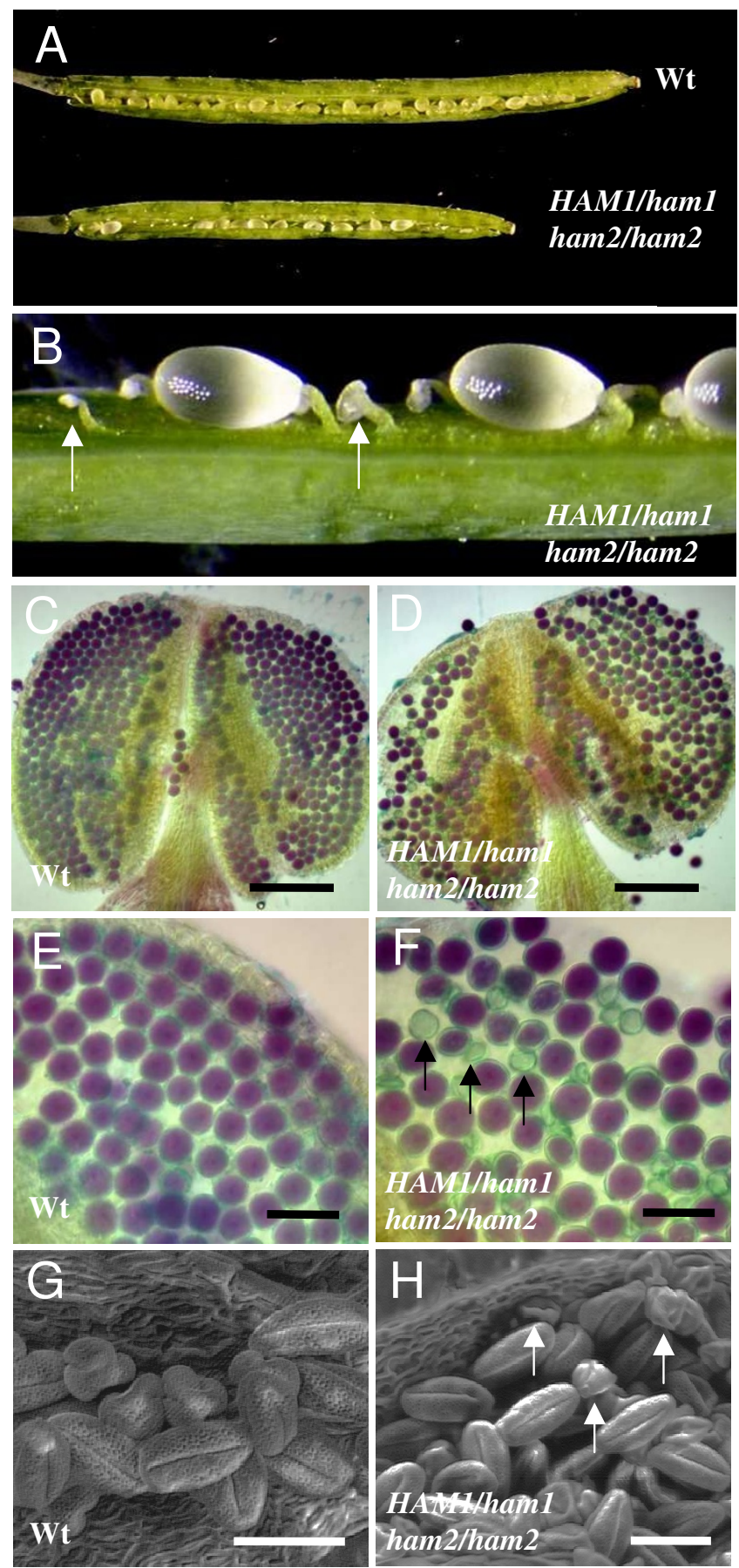

Figure 3

Phenotypes induced by mutations in HAM genes. (A) Comparison of a wild-type (Col-0, top) and HAM I/ham I-I; ham 2 I ham2 sesquimutant silique (bottom). (B) Detail of a sesquimutant silique showing the presence of aborted ovules (arrow). Viability of mature pollen grains in thesesquimutant (D) compared to wild-type (C). Pollen grains were isolated from the anthers of opened flowers and examined by Alexander staining. Viable pollen grains were stained as purple and dead pollen grains are dark green. Bars: $100 \mu \mathrm{m}$. High magnification detail of pollens from wild-type (E) and the HAMI/ham I-I; ham2/ham2 mutant (F) showing the presence of $50 \%$ wild type and $50 \%$ shrunken, aborted pollen (arrows) in the mutant anthers. Bars $=50 \mu \mathrm{m}$. Scanning electron microscopy of pollen grains collected from wild-type (G) and HAMI/ham I-I; ham2/ham2 anthers (H). Approximately one-half of pollen grains were abnormally developed in the sesquimutant anthers (arrows). Bars: $25 \mu \mathrm{m}$. 

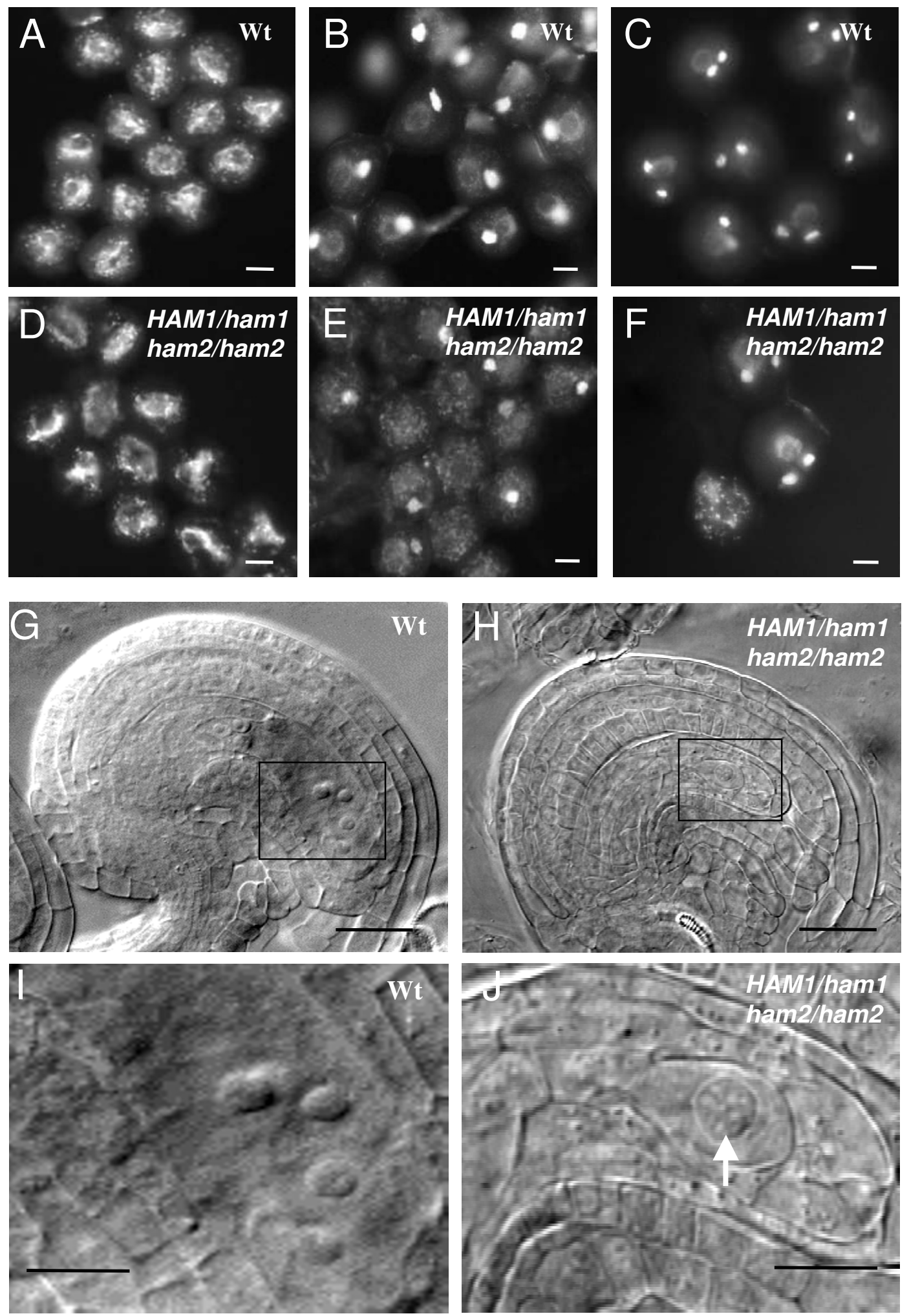

Figure 4 (see legend on next page) 
Figure 4 (see previous page)

Analysis of gametophyte development in ham sesquimutants. (A-F) Analysis of pollen development by DAPI staining. Pollen grains were released from anthers, stained with DAPI, and visualized under a light microscope equipped with a UV fluorescent filter. At uni-nucleate stage, microspores of wild-type (A) and HAMI/ham I-I; ham2/ham2 plants (D) were indistinguishable. In contrast to wild-type microspores (B and C), HAM I/ham I-I; ham2/ham2 plants contain approximately one-half of arrested microspores (arrows) at the bicellular $(\mathrm{E})$ and tricellular pollen stages (F). Bars: $10 \mu \mathrm{m}$. (G-J) Cleared whole mounts of wild-type and ham sesquimutant ovules. Mature ovules at stage $\mathrm{G} 7$ of wild-type (G) and HAMI/ham I-I; ham 2/ham2 mutant (H). Bars: $40 \mu \mathrm{m}$. Images I and J are enlargements of boxed sections in G and H respectively. Bars: $20 \mu \mathrm{m}$. (I) Magnified section shows the presence of central cell nucleus, two synergid nuclei and the egg cell nucleus in wild-type ovule. (J) An ovule from ham sesquimutant at the same stage showing the presence of only one nucleus (white arrow). No other nuclei were visualized at other focal planes.

celled mature embryo sac (female gametophyte) at female gametophyte stage 6 (FG6; [34]). The analysis of ovule development of ham 1 and ham 2 single mutants, using a chloral hydrate clearing protocol and Normarski optics, indicated that megasporogenesis occurred normally in single ham mutants (data not shown). In the ovules of sesquimutants bearing one copy of either HAM1 or HAM2, meiosis always resulted in a single surviving megaspore and as occurred in wild-type, only one of them survived. Initial abnormalities in megagametogenesis were observed only after the completion of meiosis. While half the ovules in both HAM1/ham1-1; ham2/ham2 and ham11/ham1-1; HAM2/ham2 siliques were mature showing a wild-type size and shape (Fig. 4G and 4I), the remaining ovules contained only one nucleus localized to the micropylar pole (corresponding to the stage FG1; Fig. 4H and $4 \mathrm{~J})$. They produced the $50 \%$ aborted ovules (Fig. 3B). These observations suggest that, as observed for the male gametophytic development, the degeneration of the ovule in ham1ham 2 double mutants occurs after the uninucleated stage before the first mitosis.

\section{Expression pattern of HAM genes}

The HAM1 and HAM2 mRNA levels in different organs and tissues were too low to be detected by Northern blots. RT-PCR experiments were used to analyse the expression pattern of HAM genes. Fig. 5 shows that HAM1 and HAM2 genes displayed a similar expression pattern in the different tested organs, with higher expression in flowers compared to leaves, stems and roots and in younger growing leaves compared to mature leaves.

Transgenic Arabidopsis lines were also generated to express the $\beta$-glucuronidase (GUS) reporter gene under the control of HAM1 or HAM2 promoter. About $1 \mathrm{~kb}$ DNA fragments encompassing the putative promoter regions of HAM genes were fused to the GUS coding sequence and these constructs were introduced into Col-

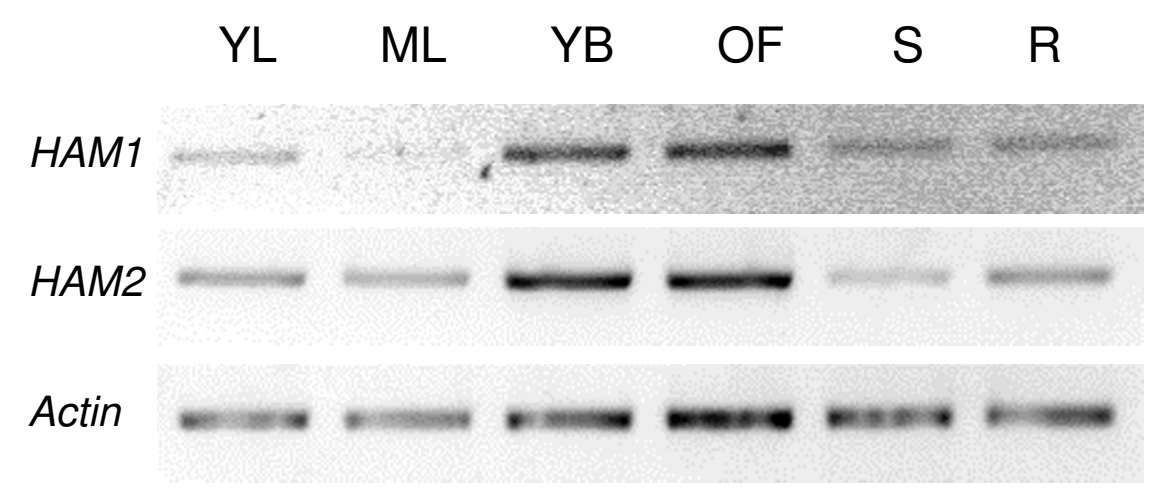

\section{Figure 5}

RT-PCR detection of HAM mRNA in different organs. HAMI and HAM2 mRNA in wild-type (Col-0) were detected by RT-PCR with primer pairs PI-P3 (HAMI) and P4-P6 (HAM2). The different organs tested are young leaves (YL), mature leaves (ML), young floral buds (YB), open flowers (OF), stems (S) and roots (R). Actin mRNA levels detected by RT-PCR are shown as controls. 
0 . A reproducible and overlapping expression pattern was found in three independent reporter lines for each promoter. Under standard growth conditions, promoter activity was detected in the shoot apex of the seedlings as well as in the cotyledons and leaves (Fig. 6A, B). In leaves, a patchy expression pattern was observed which corresponded to strong GUS staining at the basis of the trichomes (Fig. 6B). GUS activity was never detected in the hypocotyls and petiole. A faint GUS signal was occasionally detected in root hairs (Fig. 6A) but never in the internal root tissues. By contrast, GUS activity was strong in developing flowers, particularly in the anthers and gynoecia but not in mature flowers (Fig. 6C) in which a slight GUS activity was localized to the stigma. Transversal sections confirmed the GUS staining in developing gynoecia (Fig. 6D) and young pollens (Fig. 6E) and the absence of GUS expression in mature tricellular pollen grains (Fig. $6 \mathrm{~F})$.

\section{Discussion}

The MYST family of HATs has been intensively studied because of its broad conservation and its involvement in multiple aspects of animal development (Reviewed in [15]). Although the HAT activity of the Arabidopsis MYST proteins HAM1 and HAM2 have been demonstrated in vitro [28], the in vivo roles of the proteins have not yet been addressed. Here, we initiated a functional characterization of the MYST gene family in Arabidopsis.

Growing genomic sequence data indicates that most eukaryotes had multiple MYST representatives. In order to gain insight into the origin and evolution of the MYST proteins, we combined phylogenetic sequence analysis and structural comparisons to determine the relationships among different members. Such phylogenetic analysis has been already performed by Sanjuan et al. [35], but it was realized with a limited number of data and do not provide precise links between clades. Our phylogenetic analysis suggests that Eukaryotes acquired 3 ancestral MYST sequences (Fig. 1A). It appears that one of these ancient sequences has been duplicated more recently, after the separation of Teleostei from Archausauria and Mammals. It seems to, that one of these sequences has been lost during early plant evolution, before the emergence of Prasinophyceae, followed by the lost of a second one before the emergence of Bryophytes. An alternative hypothesis would be a unique sequence at the beginning of the green lineage, with the acquisition of second sequence by green algae, followed by the lost of one of these sequences (type $\mathrm{Ot2} / \mathrm{Ol} 2$ ) later during the green lineage evolution. This hypothesis suggests also the presence of three sequences before the emergence of Fungi and Metazoans.

The plant genomes were found to encode one or two MYST proteins whereas fungal genomes were found to have one to three, and animal genomes one to five. Thus, the number of plant MYST family is within the range found in other eukaryotic organisms but at the lower end of this range. The degree of evolutionary change differs significantly among MYST gene families. At one extreme, the MYST family has been amplified in Mammals and Drosophila as compared to two members in Arabidopsis. Moreover domain and phylogenetic analyses of the MYST-type proteins revealed only one class of these proteins in plants, as compared to 3 classes in Insects and Mammals. This suggests that plant may have conserved the functions of their ancestral homologues and that Arabidopsis MYST proteins may be involved in a wide range of cell functions which are assumed by different proteins in mammals. An important point is that we do not detect sequences of other HATs from Angiosperms inserted in the phylogenetic tree built with sequences of the MYST family. This suggests a very old age of the MYST sequences, which were clearly separated from other families of HAT.

In order to study the biological function of the two plant MYST proteins, we performed a genetic analysis using Arabidopsis mutants. The study has shown that HAM1 and HAM2 are functionally redundant and the presence of at least one functional HAM gene is required for the plant, as single ham 1 or ham 2 mutant plants are viable and have a wild-type phenotype, while no double mutant seedling was recovered. ham1ham 2 double mutation was not inherited because it caused mitotic defects in the mega and microgametophyte development as observed in individuals that contained a single wild-type copy of either HAM1 or HAM2. During ovule development in HAM1/ ham1; ham2/ham 2 or ham1/ham1; HAM2/ham2, abnormalities were detected after meiosis but before the first mitotic division in megagametogenesis. They produced $50 \%$ of aborted ovules ham 1 ham 2 . On the male side, pollen meiosis also appeared normal, while microsporogenesis was arrested also after microspores release but before the first pollen mitosis. In contrast to megagametogenesis, part of the ham 1ham 2 male gametes were able to produce normal pollen and were inherited.

Thus, in Arabidopsis, HAM proteins are redundantly required post-meiotically for important cellular processes during gametophytic development. However, the identification of HAM1/ham1; ham2/ham2 and ham1/ham1; HAM2/ham 2 individuals, and the data collected from outcrossing eliminated the possibility of a complete male gametophytic lethal phenotype, although there was some implication of high gametophytic lethality from the sesquimutant plants. Given that in both mutants, the two TDNA insertion sites are located at the beginning of the genes, before the HAT domain, it is unlikely that the truncated proteins HAM1 and HAM2 retain a partial HAT activity in the mutants. One possible explanation for the 


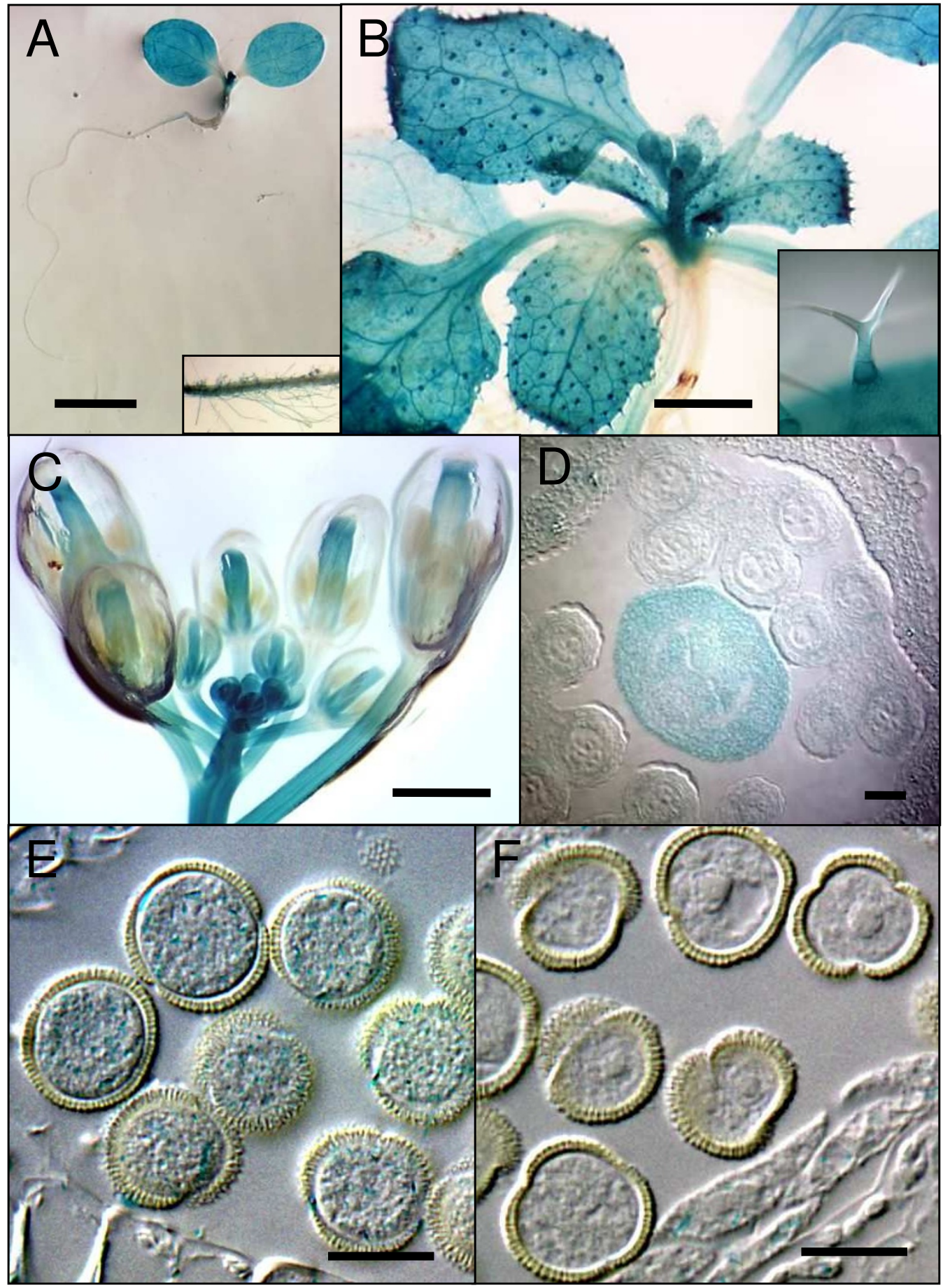

\section{Figure 6}

Expression pattern of the HAM::GUS genes. (A) Seedling of one-week-old harbouring a HAM I::GUS fusion grown in vitro. Boxed section represents a magnification of stained root hairs. Bar: $250 \mu \mathrm{m}$. (B) Three week-old plant grown in vitro. Boxed section represents a close-up view on a stained trichome. Bar: I mm. (C) Floral tissue of a 5-week-old plant. Bar: I mm. (D) Section of HAMI::GUS young floral bud at the stage of tetrad. Bar: $50 \mu \mathrm{m}$. (E-F) cleared whole mount of young (E) and mature pollen grains $(F)$ showing the decreased of GUS expression during the pollen maturation. Bars: $25 \mu \mathrm{m}$. 
genetic complexity is the diffusion of trace amounts of functional protein from surrounding heterozygous tissues into the gametes [36,37]. It is also possible that meiotic cells contain a pool of proteins or mRNA that allows several rounds of nuclear division to occur before the effect of the mutation can be observed [38].

A possible involvement of the MYST protein in the gametogenesis has been recently suggested in mammals. The two human MYST proteins, Tip60 and Mof, related to HAM (Fig. 1), are both very highly expressed during sperm development compared to other organs [15]. Human MYST4, also named MOZ2 or MORF is also localized into specialized cells of the ovary and testis and may contribute to important and specific acetylation events during gametogenesis [24]. However, these reports are based only on pattern of genes expression and protein localization. The phenotypes of Arabidopsis knock-out mutants, described here, are the first demonstration of an essential role of MYST proteins in gametogenesis.

Using transgenic plants expressing the GUS reporter gene, a strong promoter activity of HAM genes was observed in young flowers, particularly during gynoecium and anther development, which is consistent with the requirement of HAM1 and HAM2 for gametogenesis. However, GUS expression and RT-PCR results have shown that HAM genes expression was not restricted to cells involved in gametogenesis. An expression pattern was also observed during vegetative development. Interestingly, a GUS activity was detected in trichoblasts (root hairs and trichomes). We can note that despite the differences in morphology and distribution, this kind of cells is specified by a similar set of genes [39]. GUS activity was also detected in shoot apex, cotyledons and leaves but neither in the primary root meristem nor the emerging lateral roots. These results indicate that HAM1 and HAM2 expression occurs mainly in some, but not all, proliferative tissues. The broad expression pattern of HAM genes suggests that they may be involved in several aspects of development, rather than gametophyte-specific genes.

Taking these GUS data together with the abnormal nuclear division in ham1ham2 gametes it is tempting to speculate a role for the MYST family in the control of key cellular process such as cell cycle control. This essentiality of the MYST pathway in plants is consistent with data related to the functions of MYST proteins in other organisms [16]. The closest homologues of Arabidopsis MYST proteins in Homo sapiens are Tip60 and HsMOF (Fig. 1). Several recent papers provide evidence that Tip60 is a key protein in regulating cell cycle progression in mammals [15]. Tip60 is also intimately involved in the cellular response to DNA damage. Additionally, in Drosophila the histone acetyltransferase activity of Tip60 is specifically required for the exchange of histones during doublestrand break repair [40]. We do not know whether plant HAM proteins are directly involved in these processes. Although the ontogeny of gametophyte development has been defined in Arabidopsis, the molecular mechanisms regulating cell cycle progression are not well understood especially concerning how micro- and macrospores pass through each phase of the cell cycle, such as the G1/S transition during the unicellular stage. A phenotype with defects in the formation of male and female gametophyte due to interphase arrest of mitotic cell cycle at early stages (FG1 stage of megagametogenesis and PMI stage of microgametogenesis) will facilitate our understanding of the determining factors of gametophyte development. A highly similar phenotype has been recently described for the rhf1arhf2a double mutants which are defective in two RING-finger E3 ligases that mediate the degradation of the meiosis-accumulated ICK4/KRP6 that is essential to ensure cell cycle progression during gametogenesis [41]. Likewise, it has been recently demonstrated that HAM1 and HAM2 preferentially acetylate histone $\mathrm{H} 4$ lysine 5 (H4K5) in a similar fashion to the yeast homologue, Esa1 $[28,42]$. During the S-phase, newly synthesized histones $\mathrm{H} 4$ are deposited in a diacetylated isoform (at lysine 5 and 12) and it appears to be a highly conserved phenomenon in a wide range of organisms including plants $[43,44]$. These results are in agreement with a potential role of HAM1 and HAM2 during the S-phase. With abnormal nuclear divisions in ham1ham 2 gametes, it is tempting to speculate a role for the Arabidopsis MYST family in controlling key cellular processes as DNA replication. This hypothesis remains to be tested during further analysis.

\section{Conclusion}

The work presented here reveals novel properties for Arabidopsis MYST HAT. In addition to providing an extensive phylogenetic analysis of this large protein family, we provide evidence of a link between MYST and gamete formation in both male and female organs. The getting of conditional mutants with an inducible mis-expression system and the identification of the partners of these factors would also provide new tools to study the implication of MYST at the level of cellular process.

\section{Methods \\ Identification of T-DNA insertion mutants}

ham1-1 and ham 2 mutants carrying T-DNA insertions respectively within HAM1 (At5g64610; SALK_027726) and HAM2 (At5g09740; SALK_106046) were obtained from The Nottingham Arabidopsis Stock Center (NASC). ham1-2 was a GABI-KAT line (050B11) [45]. acquired from the NASC. ham1-3 (EHQ293) was obtained from the Versailles collection. The following PCR primers were used to genotype plants carrying these T-DNA insertions. ham1-1 F: 5'-ATGGTGTGCGAATCTATGACC-3'; ham1-1 R: 
5'-TCAAGGTCAAGCTGTTCAAGC-3'; ham1-2 F: 5'-TTACAGGTGGGCAAGAAG-3'; ham1-2 R: 5'-ACCATCCAGACAAAAGATTCC-3'; ham1-3 F: 5'-AAGGAAGGGCTATGGCAAAT-3'; ham1-3 R: 5'-CGTTTTACCATCCAGACAAAAG-3' ham2 F: 5'GTCGAAGAAGAGGAAAATGGG-3'; ham2 R: 5'-CATATGCCTTTGAAGCTGCTC-3'; T-DNA left border: 5'-CGATTTCGGAACCACCATCAAACAGGA-3'. All of the T-DNA mutants and wild-type plants in this study were from the Columbia ecotype Col-0 excepted for ham 1-3 mutant in the Ws background.

\section{Growth Conditions}

Arabidopsis plants were grown in a greenhouse under long-day conditions ( $16 \mathrm{~h}$ of light) at $19.5^{\circ} \mathrm{C}$ (day) and $17.5^{\circ} \mathrm{C}$ (night). For in vitro cultures, seeds were sown on 0.5 Murashige and Skoog medium, incubated at $4^{\circ} \mathrm{C}$ for $48 \mathrm{~h}$, and then transferred to growth chambers.

\section{Genomic DNA and Total RNA extraction, PCR, RT-PCR}

Arabidopsis leaves were used for genomic DNA extraction. PCR were carried out using the Promega GoTaq polymerase. Total RNA was isolated with TRIzol reagents (Invitrogen). First strand cDNA was synthesized from $3 \mu \mathrm{g}$ of total RNA using ImProm-II reverse transcriptase (Promega). Polymerase chain reaction primers specific to the predicted cDNA sequences of each gene were used. For HAM1: P1, 5'ATGGGATCGTCTGCGGATACA-3'; P2， 5'-GAATTCGTGAGAGCGAGTATCGCA-3'; P3， 5'-AGTCATCTAAGGATATGCAGA-3'. For HAM2: P4, 5'-CCTTTAACTCCTGATCAAGCTAT-3'; P5, 5'-CTACAGCGCACTCTACTGAATC-3'; P6, 5'-GACAGCCCGCTTTACTTACACA-3'. For Actin: ACT-FP, 5'ACCCAAAGGCCAACAGAGAGA-3'; ACT-RP, 5'-TGCTTGGTGCAAGTGCTGTGA-3'.

\section{Microscopy}

To examine pollen viability, pollen grains were stained with Alexander solution [46]. The pollen nuclei were stained with DAPI according to a method already describe by [47]. For observations of ovules, siliques were fixed overnight using 3:1 acetic acid: ethanol and then washed with 70\% ethanol before clearing in 8: 1: 2 chloral hydrate: glycerol: water. For scanning electron microscope (Hitachi S-3000) analysis, samples were slowly frozen at $18^{\circ} \mathrm{C}$ under a partial vacuum on the Peltier stage before observation under the environmental secondary electron detector mode.

\section{Promoters analysis}

The HAM1 and HAM2 promoters sequences used contain 1 $\mathrm{kb}$ upstream of the ATG and were amplified from Arabidopsis genomic DNA with the 5'-GCAGAATTCTCATTGTAGGTAAAAGAA-3' and 5'-GGATCCTTCTTTAGTCGGGTCGGA-3' primers for HAM1 and the 5'-GCGAATTCGTCTAACAGACTAAACGT-3' and 5'-CGGATCCTTCTCGGTCGGGTCGGAG-3' primers for HAM2. The corresponding PCR fragments were cloned into PUC19 vector and then transferred upstream the uidA gene in the plant transformation vector pPR97. The constructs were used to transform Col plants by the floral dip method. Transgenic plants were obtained on kanamycin containing medium and later transferred to soil for optimal seed production. For analysis of GUS activity, samples were prefixed in $90 \%$ acetone at room temperature for $20 \mathrm{~min}$, rinsed in staining buffer without 5bromo-4-chloro-3-indolyl-_-D-glucoronic acid (X-Gluc), infiltrated with staining solution $(100 \mathrm{mM}$ sodium phosphate buffer, $\mathrm{pH} 7,5 \mathrm{mM}$ potassium ferrocyanide, $5 \mathrm{mM}$ potassium-ferricyanide, $1 \mathrm{mM} \mathrm{X-Gluc)} \mathrm{under} \mathrm{a} \mathrm{vacuum} \mathrm{for}$ $15 \mathrm{~min}$, and incubated at $37^{\circ} \mathrm{C}$ for $14 \mathrm{~h}$. After a progressive dehydration in a series ethanol concentrations up to $70 \%$, samples were cleared in 8: 1: 2 chloral hydrate: glycerol: water. For sections, the stained samples were fixed in FAA at $4{ }^{\circ} \mathrm{C}$ overnight, and then embedded in Leica historesin. Semithin sections $(3 \mu \mathrm{m})$ were cut and analyzed under a microscope.

\section{Data collection}

We searched for MYST sequences from protein databases at NCBI. 130 protein sequences were downloaded from numerous genomes. This allows to analyse sequences from Plants, Algae, Mycetozoans, Insects, Teleostei, Mammals (including Monotremata and Marsupial), Amphibia, Cnidarian, Echinozoa, Fungi, Plathelminthes, Nematods, Alveolata, Archausauria and Ascidiaceae. Bacteria do not have counterpart to the MYST proteins.

\section{Alignment and phylogenetic analysis}

The amino-acid alignment was conducted using Clustal $[48,49]$ with default parameters. The generated alignment was adjusted manually. Amino acid alignments of the MYST domain were used as the basis for classifying MYST proteins. The unrooted tree was created using the PhYML algorithm and the maximum likelihood method [50]. To assess support for each node, bootstrap analysis were performed using 500 bootstrap replicates. A bootstrap value of $70 \%$ is likely to be correct at the $95 \%$ level, and bootstrap values higher than $70 \%$ were taken as sufficient evidence for grouping.

\section{Structural analyses}

To search for domain organization in the MYST proteins, we analyzed the sequences in Pfam http:// pfam.sanger.ac.uk[51], Prosite http://www.expasy.ch/ prosite[52] and SMART http://smart.embl-heidelberg.de/ index2.cgi[52] databases.

\section{Divergence time between sequences}

To assess the age of the divergence between sequences, we estimated the level of synonymous substitutions (Ks) between the Arabidopsis thaliana HAM1 and HAM2 genes. After removing gaps in the nucleotide alignment, per-site 
synonymous (Ks) and nonsynonymous (Ka) substitution rates were calculated using PAL2NAL http://coot.embl.de/ pal2nal/[54].

\section{Authors' contributions}

DL carried out mutant analysis and reporter studies, MB performed cloning for reporter studies, YH performed the phylogenetic analysis, SD participated in the cytological and microscopically studies, WK participated in the genotyping of T-DNA insertion lines, $\mathrm{D}-\mathrm{X} \mathrm{Z}$ participated in the design of study and helped to draft the manuscript, MD conceived the study, and participated in its design and coordination and wrote the manuscript. All authors read and approved the final manuscript.

\section{Additional material}

\section{Additional file 1}

List of the 105 proteins belonging to the MYST family used in our phylogenetic analysis.

Click here for file

[http://www.biomedcentral.com/content/supplementary/14712229-8-121-S1.doc]

\section{Additional file 2}

Phylogenetic tree of the plant and Mycetozoa MYST protein.

Click here for file

[http://www.biomedcentral.com/content/supplementary/14712229-8-121-S2.ppt]

\section{Additional file 3}

RT-PCR analysis of HAM1 gene expression in ham 2 homozygous mutant and of the HAM2 gene expression in the ham 1 homozygous mutant.

Click here for file

[http://www.biomedcentral.com/content/supplementary/14712229-8-121-S3.ppt]

\section{Additional file 4}

Segregation and inheritance of ham T-DNA alleles. Numbers represent plants genotyped by PCR. ham1 represent the ham1-1 allele. Het represents plants that are heterozygous at the indicated locus (Freq. Obs., frequency observed). TE, transmission efficiency of the mutant allele $=$ number of mutant alleles/number of total alleles.

Click here for file

[http://www.biomedcentral.com/content/supplementary/14712229-8-121-S4.doc]

\section{Additional file 5}

Meiotic spreads of wild-type (A to $C$ ) and ham sesquimutant (D to F). Meiotic spreads of wild-type (A to $C$ ) and ham sesquimutant ( $D$ to $F)$. No difference were detected in wild-type and mutant meiocytes during prophase I (pachytene: A and D), telophase I (B and E) and telophase II (C and F). Bars: $10 \mu \mathrm{m}$

Click here for file

[http://www.biomedcentral.com/content/supplementary/14712229-8-121-S5.ppt]

\section{Acknowledgements}

We thank Sylvie Carluer for technical assistance in the genotyping. We thank the Salk Institute Genomic Analysis Laboratory for providing T-DNA insertion mutants.

\section{References}

I. Shilatifard A: Chromatin modifications by methylation and ubiquitination: implications in the regulation of gene expression. Annu Rev Biochem 2006, 75:243-269.

2. Kouzarides T: Chromatin modifications and their function. Cell 2007, I 28(4):693-705.

3. Berger SL: The complex language of chromatin regulation during transcription. Nature 2007, 447(7 I 43):407-4I2.

4. Shahbazian MD, Grunstein M: Functions of site-specific histone acetylation and deacetylation. Annu Rev Biochem 2007, 76:75-100.

5. Sterner DE, Berger SL: Acetylation of histones and transcription-related factors. Microbiol Mol Biol Rev 2000, 64(2):435-459.

6. Pandey R, Muller A, Napoli CA, Selinger DA, Pikaard CS, Richards EJ, Bender J, Mount DW, Jorgensen RA: Analysis of histone acetyltransferase and histone deacetylase families of Arabidopsis thaliana suggests functional diversification of chromatin modification among multicellular eukaryotes. Nucleic Acids Res 2002, 30(23):5036-5055.

7. Stockinger EJ, Mao Y, Regier MK, Triezenberg SJ, Thomashow MF Transcriptional adaptor and histone acetyltransferase proteins in Arabidopsis and their interactions with CBFI, a transcriptional activator involved in cold-regulated gene expression. Nucleic Acids Res 200 I, 29(7): 1524-1533.

8. Vlachonasios KE, Thomashow MF, Triezenberg SJ: Disruption mutations of ADA2b and GCN5 transcriptional adaptor genes dramatically affect Arabidopsis growth, development, and gene expression. Plant Cell 2003, I5(3):626-638.

9. Bertrand C, Bergounioux C, Domenichini S, Delarue M, Zhou DX: Arabidopsis histone acetyltransferase AtGCN5 regulates the floral meristem activity through the WUSCHEL/AGAMOUS pathway. J Biol Chem 2003, 278(30):28246-2825I.

10. Benhamed M, Bertrand C, Servet C, Zhou DX: Arabidopsis GCN5, HDI, and TAFI/HAF2 interact to regulate histone acetylation required for light-responsive gene expression. Plant Cell 2006, I 8( I I ):2893-2903

II. Long JA, Ohno C, Smith ZR, Meyerowitz EM: TOPLESS regulates apical embryonic fate in Arabidopsis. Science 2006, 3 | 2(5779): | $520-1523$.

12. Bertrand C, Benhamed M, Li YF, Ayadi M, Lemonnier G, Renou JP, Delarue M, Zhou DX: Arabidopsis HAF2 gene encoding TATAbinding protein (TBP)-associated factor TAFI, is required to integrate light signals to regulate gene expression and growth. J Biol Chem 2005, 280(2): I 465-I 473.

13. Han SK, Song JD, Noh YS, Noh B: Role of plant CBP/p300-like genes in the regulation of flowering time. Plant $J$ 2007, 49(I): $103-14$

14. Avvakumov N, Cote J: The MYST family of histone acetyltransferases and their intimate links to cancer. Oncogene 2007, 26(37):5395-5407.

15. Thomas T, Voss AK: The diverse biological roles of MYST histone acetyltransferase family proteins. Cell Cycle 2007, 6(6):696-704

16. Pillus L: MYSTs mark chromatin for chromosomal functions. Curr Opin Cell Biol 2008, 20(3):326-333.

17. lizuka M, Stillman B: Histone acetyltransferase HBOI interacts with the ORCI subunit of the human initiator protein. J Biol Chem 1999, 274(33):23027-23034.

18. Burke TW, Cook JG, Asano M, Nevins JR: Replication factors MCM2 and ORC 1 interact with the histone acetyltransferase HBOI. J Biol Chem 200I, 276( I 8): I5397-I5408.

19. Aggarwal BD, Calvi BR: Chromatin regulates origin activity in Drosophila follicle cells. Nature 2004, 430(6997):372-376.

20. Doyon Y, Cayrou C, Ullah M, Landry AJ, Cote V, Selleck W, Lane WS, Tan S, Yang XJ, Cote J: ING tumor suppressor proteins are critical regulators of chromatin acetylation required for genome expression and perpetuation. Mol Cell 2006, 2I(I):5I-64. 
21. lizuka M, Matsui T, Takisawa H, Smith MM: Regulation of replication licensing by acetyltransferase Hbol. Mol Cell Biol 2006, 26(3): $1098-1108$.

22. Doyon Y, Selleck W, Lane WS, Tan S, Cote J: Structural and functional conservation of the NuA4 histone acetyltransferase complex from yeast to humans. Mol Cell Biol 2004, 24(5): $1884-1896$.

23. Clarke AS, Lowell JE, Jacobson SJ, Pillus L: Esa I p is an essential histone acetyltransferase required for cell cycle progression. Mol Cell Biol 1999, I9(4):25I5-2526.

24. McGraw S, Morin G, Vigneault C, Leclerc P, Sirard MA: Investigation of MYST4 histone acetyltransferase and its involvement in mammalian gametogenesis. BMC Dev Biol 2007, 7: 123.

25. Merson TD, Dixon MP, Collin C, Rietze RL, Bartlett PF, Thomas T, Voss AK: The transcriptional coactivator Querkopf controls adult neurogenesis. J Neurosci 2006, 26(44): I I359- I I 370.

26. Thomas T, Dixon MP, Kueh AJ, Voss AK: Mof (MYSTI, KAT8) is essential for progression of embryonic development past the blastocyst stage and required for normal chromatin architecture. Mol Cell Biol 2008, 28( I 6):5093-5I 05.

27. Gupta A, Guerin-Peyrou TG, Sharma GG, Park C, Agarwal M, Ganju RK, Pandita S, Choi K, Sukumar S, Pandita RK, et al:: The mammalian ortholog of Drosophila MOF that acetylates histone H4 lysine 16 is essential for embryogenesis and oncogenesis. Mol Cell Biol 2008, 28(I):397-409.

28. Earley KW, Shook MS, Brower-Toland B, Hicks L, Pikaard CS: In vitro specificities of Arabidopsis co-activator histone acetyltransferases: implications for histone hyperacetylation in gene activation. Plant J 2007, 52(4):615-626.

29. Roth SY, Denu JM, Allis CD: Histone acetyltransferases. Annu Rev Biochem 200I, 70:81-120.

30. Bowers JE, Chapman BA, Rong J, Paterson AH: Unravelling angiosperm genome evolution by phylogenetic analysis of chromosomal duplication events. Nature 2003 422(6930): $433-438$.

31. De Bodt S, Maere S, Peer Y Van de: Genome duplication and the origin of Angiosperms. Trends Ecol Evol 2005, 20(I I):59I-597.

32. McCormick S: Male Gametophyte Development. Plant Cell | 993, 5(10): | 265-1275.

33. McCormick S: Control of male gametophyte development Plant Cell 2004, 16:.

34. Christensen CA, Subramanian S, Drews GN: Identification of gametophytic mutations affecting female gametophyte development in Arabidopsis. Dev Biol 1998, 202(I): I36-I5I.

35. Sanjuan R, Marin I: Tracing the origin of the compensasome: evolutionary history of DEAH helicase and MYST acetyltransferase gene families. Mol Biol Evol 200I, I 8(3):330-343.

36. Liu CM, McElver J, Tzafrir I, Joosen R, Wittich P, Patton D, van Lammeren AA, Meinke D: Condensin and cohesin knockouts in Arabidopsis exhibit a titan seed phenotype. Plant J 2002 29(4):405-4I5.

37. Jiang L, Xia M, Strittmatter LI, Makaroff CA: The Arabidopsis cohesin protein SYN3 localizes to the nucleolus and is essential for gametogenesis. Plant J 2007, 50(6): I020-I034.

38. Liu Z, Makaroff CA: Arabidopsis separase AESP is essential for embryo development and the release of cohesin during meiosis. Plant Cell 2006, I 8(5): I213-1225.

39. Guimil S, Dunand C: Cell growth and differentiation in Arabidopsis epidermal cells. J Exp Bot 2007, 58( I 4):3829-3840.

40. Kusch T, Florens L, Macdonald WH, Swanson SK, Glaser RL, Yates JR 3rd, Abmayr SM, Washburn MP, Workman JL: Acetylation by Tip60 is required for selective histone variant exchange at DNA lesions. Science 2004, 306(5704):2084-2087.

41. Liu J, Zhang Y, Qin G, Tsuge T, Sakaguchi N, Luo G, Sun K, Shi D, Aki $S$, Zheng N, et al:: Targeted Degradation of the Cyclin-Dependent Kinase Inhibitor ICK4/KRP6 by RING-Type E3 Ligases Is Essential for Mitotic Cell Cycle Progression during Arabidopsis Gametogenesis. Plant Cell 2008.

42. Galarneau L, Nourani A, Boudreault AA, Zhang Y, Heliot L, Allard S, Savard J, Lane WS, Stillman DJ, Cote J: Multiple links between the NuA4 histone acetyltransferase complex and epigenetic control of transcription. Mol Cell 2000, 5(6):927-937.

43. Jackson V, Granner D, Chalkley R: Deposition of histone onto the replicating chromosome: newly synthesized histone is not found near the replication fork. Proc Natl Acad Sci USA 1976, 73(7):2266-2269.
44. Jasencakova Z, Meister A, Walter J, Turner BM, Schubert I: Histone $\mathrm{H4}$ acetylation of euchromatin and heterochromatin is cell cycle dependent and correlated with replication rather than with transcription. Plant Cell 2000, I 2(I I):2087-2I00.

45. Rosso MG, Li Y, Strizhov N, Reiss B, Dekker K, Weisshaar B: An Arabidopsis thaliana T-DNA mutagenized population (GABI-Kat) for flanking sequence tag-based reverse genetics. Plant Mol Biol 2003, 53(2):247-249.

46. Alexander MP: Differential staining of aborted and nonaborted pollen. Stain Technol 1969, 44(3): I I7-I 22.

47. Armstrong SJ, Jones GH: Meiotic cytology and chromosome behaviour in wild-type Arabidopsis thaliana. J Exp Bot 2003, 54(380): $1-10$.

48. Thompson JD, Gibson TJ, Plewniak F, Jeanmougin F, Higgins DG: The CLUSTAL_ $X$ windows interface: flexible strategies for multiple sequence alignment aided by quality analysis tools. Nucleic Acids Res 1997, 25(24):4876-4882.

49. Thompson JD, Plewniak F, Poch O: A comprehensive comparison of multiple sequence alignment programs. Nucleic Acids Res 1999, 27( I 3):2682-2690.

50. Guindon S, Gascuel O: A simple, fast, and accurate algorithm to estimate large phylogenies by maximum likelihood. Systematic Biology 2003, 52(5):696-704.

5I. Finn RD, Mistry J, Schuster-Bockler B, Griffiths-Jones S, Hollich V, Lassmann T, Moxon S, Marshall M, Khanna A, Durbin R, et al:: Pfam: clans, web tools and services. Nucleic Acids Res 2006:D247-25I.

52. Hulo N, Bairoch A, Bulliard V, Cerutti L, De Castro E, LangendijkGenevaux PS, Pagni M, Sigrist C]: The PROSITE database. Nucleic Acids Res 2006:D227-230.

53. Schultz J, Milpetz F, Bork P, Ponting CP: SMART, a simple modular architecture research tool: identification of signaling domains. Proc Natl Acad Sci USA 1998, 95(I I):5857-5864.

54. Suyama M, Torrents D, Bork P: PAL2NAL: robust conversion of protein sequence alignements into the corresponding codon alignement. Nucleic Acid Res 2006, 34:W609-W6I2.
Publish with Biomed Central and every scientist can read your work free of charge

"BioMed Central will be the most significant development for disseminating the results of biomedical research in our lifetime. "

Sir Paul Nurse, Cancer Research UK

Your research papers will be:

- available free of charge to the entire biomedical community

- peer reviewed and published immediately upon acceptance

- cited in PubMed and archived on PubMed Central

- yours - you keep the copyright
BiolMedcentral 